\title{
Quantitative circumferential strain analysis using ATP-stress/rest 3-Tesla tagged magnetic resonance to evaluate regional contractile dysfunction in ischemic heart disease
}

\author{
Masashi Nakamura ${ }^{*}$, Tomoyuki Kido $^{2}$, Teruhito Mochizuki ${ }^{1}$ \\ From 18th Annual SCMR Scientific Sessions \\ Nice, France. 4-7 February 2015
}

\section{Background}

We evaluated whether quantitative circumferential strain (C-strain) analysis using adenosine triphosphate (ATP)stress/rest 3-Tesla (3-T) tagged magnetic resonance (MR) can depict myocardial ischemia as contractile dysfunction on stress. We evaluated whether it can differentiate nonischemia, myocardial ischemia and infarction. We assessed its diagnostic performance in comparison with ATP-stress myocardial perfusion MR and late gadolinium enhancement (LGE)-MR.

\section{Methods}

In 38 patients suspected of having coronary artery disease (CAD), tagged MR and perfusion MR under ATP-stress and rest conditions and LGE-MR imaging were performed. The peak negative value (\%) of the circumferential strain (C-strain) during a cardiac cycle and the time-topeak $\mathrm{C}$-strain were measured in the left ventricle using short-axis tagged images during ATP-stress and at-rest conditions. Myocardial segments were categorized as nonischemic $(\mathrm{n}=485)$, ischemic $(\mathrm{n}=74)$, or infarcted $(\mathrm{n}=$ 49) from the results of perfusion MR and LGE-MR.

\section{Results}

In non-ischemic segments, C-strain was significantly greater during ATP-stress $(-15.9 \pm 3.1 \%)($ mean $\pm \mathrm{SD})$ than at-rest $(-14.0 \pm 3.2 \%, \mathrm{p}<0.001)$ imaging. Conversely, in ischemic segments, C-strain was significantly lower during ATP-stress $(-13.9 \pm 3.2 \%)$ than at-rest $(-15.4 \pm 3.1 \%, \mathrm{p}<0.01)$ imaging.
Under both ATP-stress and at-rest conditions, $\mathrm{C}$-strain values in infarcted segments were significantly lower than those in non-ischemic and ischemic segments. Under ATP-stress, C-strain in non-ischemic segments was significantly greater than that in ischemic segments. However, under at-rest conditions, there was no significant difference between ischemic and nonischemic segments.

Cutoff values of $-12.0 \%$ for at-rest C-strain and $49.4 \%$ for at-rest time-to-peak $\mathrm{C}$-strain allowed differentiation between infarcted segments from non-ischemic and ischemic segments with sensitivities of $79 \%$ and $61 \%$, specificities of $76 \%$ and $91 \%$, accuracies of $76 \%$ and $88 \%$, and areas under the curve (AUCs) of 0.81 and 0.75 , respectively. The differences in $\mathrm{C}$-strain values between ATP-stress and at-rest conditions (stress-rest C-strain) in non-ischemic segments $(-1.78 \pm 2.45 \%)$ were significantly smaller than in segments with ischemia $(+1.47 \pm$ $1.89 \%, \mathrm{p}<0.001)$. A cutoff value of $+0.3 \%$ for the stress -rest C-strain value could differentiate segments with ischemia from non-ischemic segments with a sensitivity of $75 \%$, a specificity of $82 \%$, an accuracy of $82 \%$, and an AUC of 0.86 .

\section{Conclusions}

C-strain analysis using tagged MR can quantitatively assess contractile dysfunction in ischemic and infarcted myocardium.

\section{Funding}

N/A.

${ }^{1}$ Radiology, Ehime University, Toon, Japan

Full list of author information is available at the end of the article 

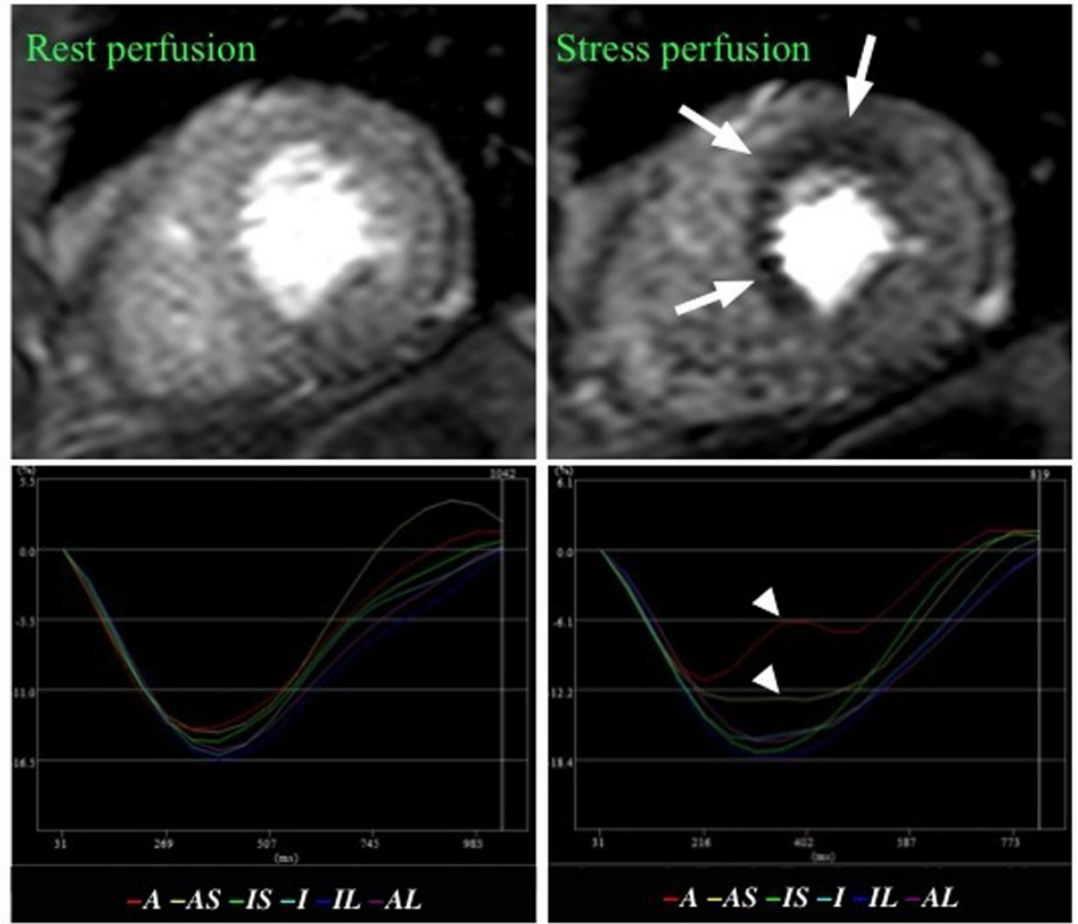

Figure $1 \mathrm{~A}$, anterior; AS, anteroseptal; IS, inferoseptal; I, inferior; IL, inferolateral; AL, anterolateral

\section{Authors' details}

'Radiology, Ehime University, Toon, Japan. ${ }^{2}$ Saiseikai Matsuyama Hospital, Matsuyama, Japan.

Published: 3 February 2015

doi:10.1186/1532-429X-17-S1-Q64

Cite this article as: Nakamura et al:: Quantitative circumferential strain analysis using ATP-stress/rest 3-Tesla tagged magnetic resonance to evaluate regional contractile dysfunction in ischemic heart disease.

Journal of Cardiovascular Magnetic Resonance 2015 17(Suppl 1):Q64.
Submit your next manuscript to BioMed Central and take full advantage of:

- Convenient online submission

- Thorough peer review

- No space constraints or color figure charges

- Immediate publication on acceptance

- Inclusion in PubMed, CAS, Scopus and Google Scholar

- Research which is freely available for redistribution 